\title{
Observation of Long-Range Dust Transport from Mesopotamia and Arabian Peninsula Toward Tehran, Iran
}

\author{
Hossein Panahifar ${ }^{1, *}$ and Hamid Reza Khalesifard $^{1,2, * *}$ \\ ${ }^{1}$ Department of Physics, Institute for Advanced Studies in Basic Sciences, 4513766731 Zanjan, Iran \\ ${ }^{2}$ Center for Research in Climate Change and Global Warming (CRCC), Institute for Advanced Studies in Basic Sciences, \\ 4513766731 Zanjan, Iran
}

\begin{abstract}
Continuous vertically resolved aerosol measurements using lidar were performed in Tehran, Iran. Lidar results has been used in combination with particulate matter monitoring, synoptic meteorology observation as well as satellite-based measurements. The aerosol types are classified by their optical properties. The volume linear depolarization ratio (VLDR) at $532 \mathrm{~nm}$ lies mostly between $0.05-0.10$. These results show that mostly urban pollution mixed with particles are present in the atmosphere above Tehran. During dust events, the VLDR at $532 \mathrm{~nm}$ lies between 0.20-0.35.
\end{abstract}

\section{Introduction}

Dust aerosols play a crucial role in the global and regional climate. Dust is a major contributor to the global aerosol loading, influencing atmospheric radiation balance and decreasing visibility $[1,2]$. The Iran Plateau $\left(\sim 26^{\circ}-36^{\circ} \mathrm{N}\right.$, $\left.\sim 45^{\circ}-61^{\circ} \mathrm{E}\right)$ is part of the dust belt and strongly affected by dust storms. It is also has known as source of dust storm in the mentioned region [3-5]. Mesopotamia and the Arabian Peninsula can be considered as main external sources that have considerable impacts on dust loading into the atmosphere above the Iran Plateau. In this regard, some studies have shown that the Mesopotamian region accounts for more than $80 \%$ of observed dust events in Northwest Iran [6-8]. There are also several dust sources inside the Iran Plateau which are mainly located in the vicinity of dried and seasonal lakes $[4,9]$. Therefore, aerosol observations are extremely valuable within this region. Its results can be used to characterize dust and understand its regional transport pattern.

This research includes vertically resolved depolarized lidar measurements as well as synoptic meteorology and in-situ particulate matter concentration measurements in Tehran $\left(\sim 35.5^{\circ}-35.8^{\circ} \mathrm{N}, \sim 51.1^{\circ}-51.6^{\circ} \mathrm{E}\right)$, the capital and most populated city of Iran. As shown in Fig. 1, Tehran is a mountainside city and its elevation ranges from 900 $\mathrm{m}$ amsl (above mean sea level) in south to $1800 \mathrm{~m}$ amsl in the northern part. The city is suffering from atmospheric urban pollution arising from rapid urbanization during the last decades. Urban pollution and polluted dust are the dominant contributors to the atmospheric aerosol burden most of the time, especially during the cold season. Dust particles are the dominant atmospheric aerosol fraction during the warm season [13]. The number of occurrence

\footnotetext{
*e-mail: h.panahifar@iasbs.ac.ir

**e-mail: khalesi@iasbs.ac.ir
}

of episodes characterizes by horizontal visibility less than $10 \mathrm{~km}$ in Tehran for the period 2006-2009 has been investigated [14]. They found that there was a significant number of cases when horizontal visibility is between 3 and $10 \mathrm{~km}$. Eventually they claimed that the city of Tehran is repeatedly impacted by dust storms.

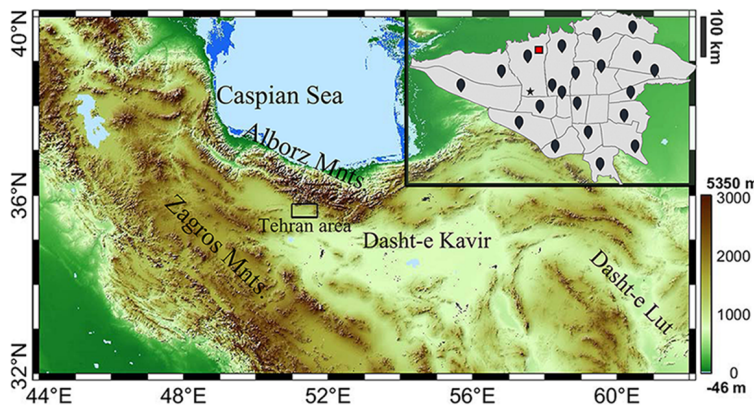

$\square$ IASBS LidAR Station $\star$ Mehrabad Airport Air quality control Stations

Figure 1. Topographic map of North Iran provided by SRTM (Shuttle Radar Topography Mission) with the location of AQCC stations distributed over the city of Tehran.

This type of studies which has been using in- situ measurements, has revealed valuable information about the particle type and concentrations at ground level. However, the depolarization lidar is a very powerful remote sensing tool to characterize the distribution profile of the atmospheric particulate matters as well as their type. The technique permits the discrimination of desert dust or polluted dust from other aerosols such as biomass-burning smoke, marine aerosol particles, and urban haze [15-18].

This article introduces lidar measurements in Tehran that are focused on the recorded dust event on 22 April 2015. The time-height series of VLDR, backward trajectories, results from meteorological model and satellite data are 
also presented. In Sect. 2 of this article, the measurement site, the lidar system, and the used auxiliary data are described. In Sect. 3, results obtained from the lidar observation are discussed in detail. The conclsion comes in Sect. 4.

\section{Instruments and Methods}

The lidar measurement site was located at $35.7669^{\circ} \mathrm{N}$, $51.3118^{\circ} \mathrm{E}$, at an altitude $1430 \mathrm{~m}$ amsl in Northwest Tehran and inside an urban area (Fig. 1). A depolarization lidar is used for continuous lidar measurements from 11 November 2014 until 11 March 2016 [13]. The system emits linearly polarized light at $532 \mathrm{~nm}$, and 1064 $\mathrm{nm}$ wavelength generated by a Nd:YAG laser and 2nd harmonic generators. The lidar data were acquired with vertical and temporal resolution of $15 \mathrm{~m}$ and $30 \mathrm{~s}$ respectively. The attenuated backscatter coefficient (abbreviated as $\mathrm{ABC}$ ), and volume linear depolarization ratio (VLDR) at $532 \mathrm{~nm}$ have been calculated from the lidar recordings for monitoring the atmospheric particulate matters [19].

Additionally, regular synoptic and upper air measurements were carried out at Mehrabad station (Fig. 1). At the same time, hourly averaged $\mathrm{PM}_{2.5}$ and $\mathrm{PM}_{10}$ concentration were obtained from Tehran Air Quality Control Company (AQCC). During the measurement period, AQCC had 21 automated air monitoring stations over the city. The regional distribution of dust aerosols (mobilization and transport) is described using complementary satellite products. Aerosol Optical Depth (AOD) at $550 \mathrm{~nm}$ taken from the Moderate Resolution Imaging Spectroradiometer (MODIS) Deep Blue collection (MOD08, MYD08) available from the Giovanni Web portal (http://disc.sci.gsfc.nasa.gov/giovanni). The data used here were re-gridded onto a $1^{\circ} \times 1^{\circ}$ grid and available at daily resolution.

Information on synoptic scale meteorological conditions were taken from 6-hourly ECMWF (European Centre for Medium-Range Weather Forecasts) reanalysis of horizontal winds at the surface and $500 \mathrm{hPa}$. Wind speeds can provide valuable information regarding the potential activation of given dust sources at the regional scale.

\section{Results}

The time-height series of volume depolarization ratio at $532 \mathrm{~nm}$ wavelength recorded in Tehran between 20:30 UTC on 21 April 2015 and 11:50 UTC on 22 April 2015 are presented in Fig. 2a. The increase in value of VLDR indicates that a dust layer arrived around 02:00 UTC on 22 April at an altitude of 2-3 km agl (above ground level) over the lidar station. After that time, the dust layer dropped down during passing over the lidar measurement site. Fig. 2b depicts the time-series of surface wind speed, $\mathrm{PM}_{10}$ concentration and horizontal visibility with hourly resolution. The figure clearly illustrates that by arrival of the dust storm over the city, the concentration level of $\mathrm{PM}_{10}$ increased to the values higher than $200 \mu \mathrm{gm}^{-3}$. The surface wind speed also went up to $8 \mathrm{~m} / \mathrm{s}$ and as a consequence, the horizontal visibility dropped down to lower than $4 \mathrm{~km}$ at Mehrabad station.
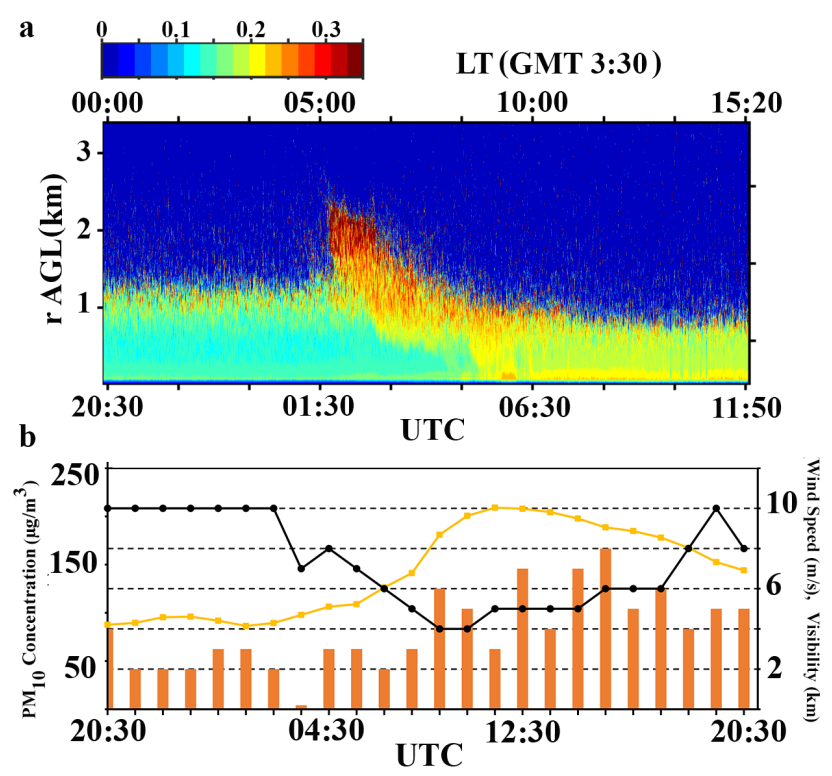

- Wind Speed - PM10 Concentration $\rightarrow$-Visibility

Figure 2. a) Time evolution of volume depolarization ratio between 20:30 UTC on 21 April 2015 and 11:50 UTC on 22 April 2015. b) Time-series of ground based measurements with hourly resolution, based on Mehrabad synoptic and reports from AQCC stations.

The HYSPLIT backward trajectories in Fig. 3a and the EUMETSAT supplementary movie are indicating that the observed dust plume at 02:00 UTC in Fig. 2a, is transported to Tehran from the region in south of the Mesopotamia and north of the Arabian Peninsula. The HYSPLIT backward trajectories started on 22 April 2015 at altitudes of $2500 \mathrm{~m} \mathrm{agl}$ and $2000 \mathrm{~m}$ agl are returning back to the Arabian Peninsula and south of the Mesopotamia respectively (Fig. 3a).
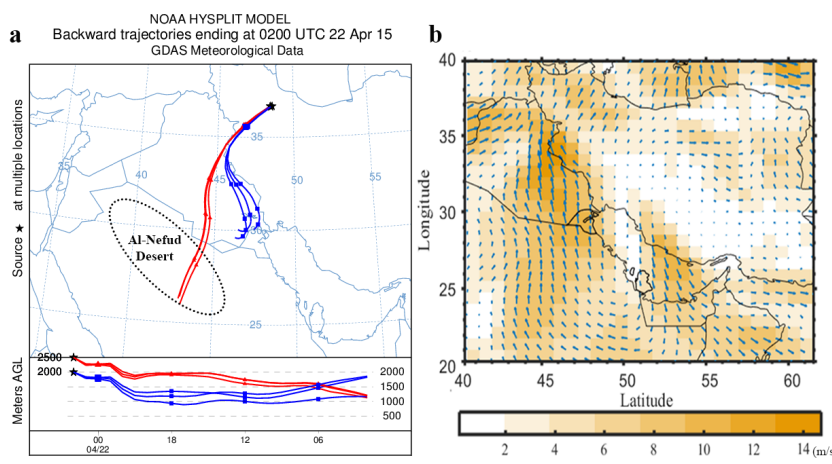

Figure 3. a) $24 \mathrm{~h}$ HYSPLIT backward trajectories arriving at Tehran at 02:00 UTC on 22 April 2015 at 2.5 and $2 \mathrm{~km}$ height. b) ECMWF reanalysis of horizontal wind speed (color) and direction (arrows) on 06:00 UTC 21 May 2015 at $10 \mathrm{~m}$ above the surface.

ECMWF reanalysis for 06:00 UTC on 21 April 2015 (Fig. 3b) show that a very strong surface wind had blown over Al-Nefud desert located along northern border of Saudi Arabia with Iraq. The winds speed reached almost 
up to $14 \mathrm{~m} / \mathrm{s}$ and had the potential to activate dust sources. The wind fields at $500 \mathrm{hPa}$ (not shown) clearly confirms that the lofted dust layer can pass over the Zagross mountains (crest line $3500 \mathrm{~m} \mathrm{agl}$ ) and subsequently reach to the central part of Iran.

This is corroborated by the MODIS derived AOD on 21 and 22 April 2015. Dialy MODIS Aqua and Terra Deep blue AODs are shown in Fig. $4 \mathrm{a}$ and $4 \mathrm{~b}$ for the mentioned dates. The areas with AOD $>1$ in Fig. 4a are mostly in North Saudi Arabia and South Iraq. Fig. 4b also shows that the dust activity is quite intensified over the Peninsula and the AOD is considerably increased over north an central parts of Iran.

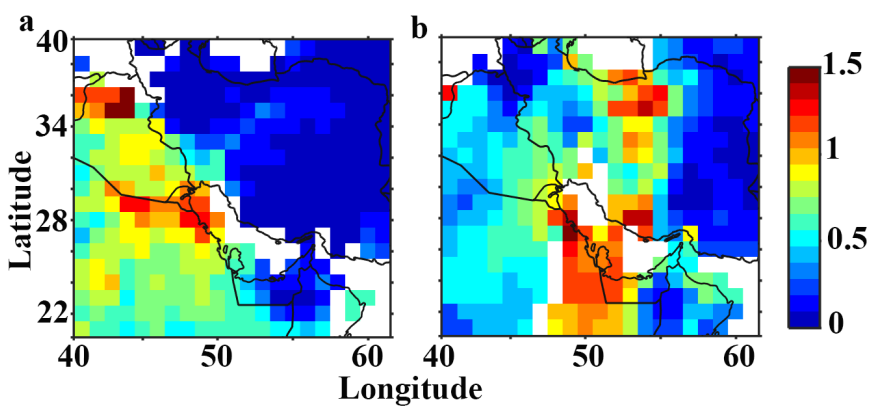

Figure 4. MODIS Terra daily AOD at $550 \mathrm{~nm}$ for (a) 21 April 2015 and (b) 22 April 2015. Deep blue AOD for land surfaces, MODIS black target AOD for sea surfaces.

The $\mathrm{ABC}$ and depolarization ratio from nighttime CALIOP measurements on 21 April 2015 are shown in Fig. 5a and Fig. 5b respectively. The figures reveal that a lofted dust layer (up to $5 \mathrm{~km}$ altitude) is present over North Saudi Arabia and south of $\operatorname{Iraq}\left(\sim 28^{\circ} \mathrm{N}-32^{\circ} \mathrm{N}\right)$. Fig. 5b shows that the CALIOP recordings are in good consistence with VLDR measured by our lidar station $(0.20<\mathrm{VLDR}<0.35)$. It also corroborates the large AOD values observed with MODIS over Iraq and Saudi Arabia.

\section{Summary and Conclusion}

For the first time, continuous depolarization lidar observations were performed over a long-term period in the highly polluted atmosphere over Tehran, Iran. In addition to the urban pollution, frequent dust storms also influence the atmosphere of the city. Here we have reported a long range transport of dust particles from the Arabian Peninsula and south of Mesopotamia toward Tehran that happened on 22 April 2015. The records of our lidar station show that the VLDR for these dust particles are about 0.35 when the layer is at altitude of $2.5 \mathrm{~km} \mathrm{agl}$ high above the boundary layer, but as it is descending and mixing with the urban pollution the VLDR decreases down to 0.2 which still quite larger than the corresponding value for anthropogenic particles. CALIOP recordings and MODIS deep blue AODs also confirm the formation of a dense dust plume on 21 and 22 April 2015 in the north of the Arabian Peninsula and HYSPLIT back trajectories demonstrate how the plume may be transported to the Iran Plateau.
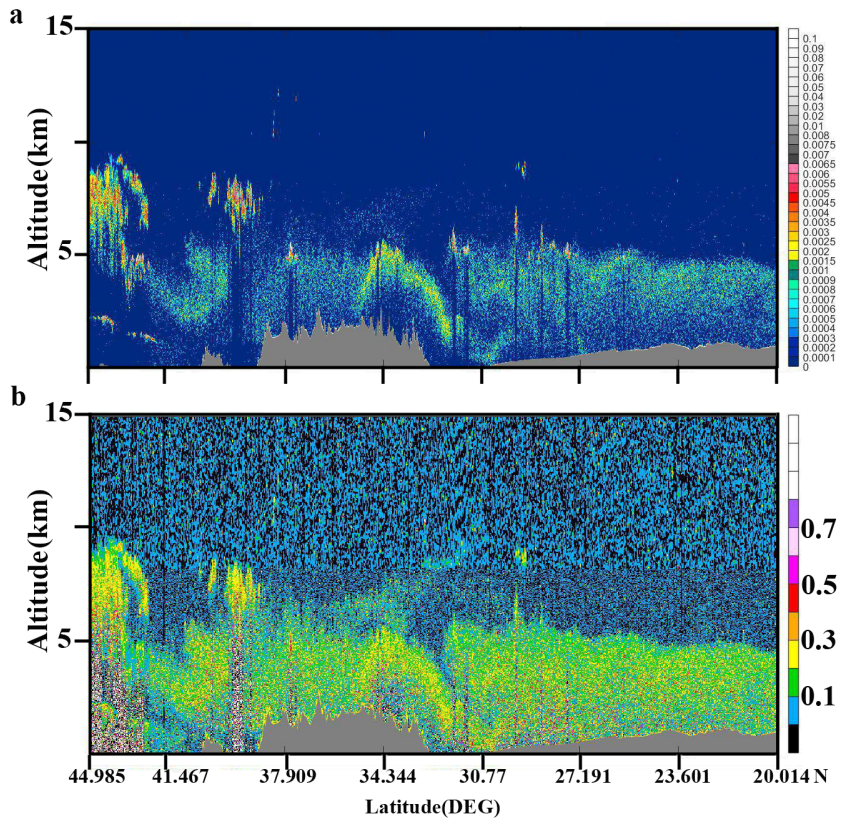

Figure 5. Vertical cross section of CALIOP recoding (at $532 \mathrm{~nm}$ ) around 22:49 UTC on 21 April 2015. a) Total attenuated backscatter. b) Depolarization ratio.

\section{Acknowledgements}

The authors appreciate Ruhollah Moradhaseli for valuable discussions. Authors also express their gratitude to the MODIS mission scientists and associated NASA personnel for the production of the data used in this research effort. The European Centre for Medium-Range Weather Forecasts (ECMWF) is acknowledged for making the meteorological analyses available from their data server. The authors also would like to appreciate AQCC for their valuable particulate matter measurements over Tehran.

\section{References}

[1] G. Pappalardo, A. Amodeo, S. Amoruso, L. Mona, M. Pandolfi and V. Cuomo, Annals of Geophysics 46(2), 401-413 (2003)

[2] S. Wang, J. Wang, Z. Zhou and K. Shang, Atmospheric Environment 39(3), 509-520 (2005)

[3] J.F. Leon and M. Legrand, Geophysical Research Letters 30(6), 1309 (2003)

[4] P. Ginoux, J.M. Prospero, T.E. Gill, N.C. Hsu and M. Zhao, Reviews of Geophysics 50(3), RG3005 (2012)

[5] J. Hofer, D. Althausen, S.F. Abdullaev, A.N. Makhmudov, B.I.Nazarov, G. Schettler, R. Engelmann, H. Baars, K.W. Fomba, K. Müller and B. Heinold, Atmospheric Chemistry and Physics 17(23), 1455914577 (2017)

[6] F. Abdi Vishkaee, C. Flamant, J. Cuesta, L. Oolman, P. Flamant and H.R. Khalesifard, Journal of Geophysical Research: Atmospheres 117(D3), D03201 (2012)

[7] A. Bayat, H.R. Khalesifard and A. Masoumi, Atmospheric Measurement Techniques 6(10), 2659-2669 (2013) 
[8] A. Masoumi, H.R.Khalesifard, A. Bayat and R. Moradhaseli, Atmospheric Research 120, 343-355 (2013)

[9] H. Gerivani, G.R. Lashkaripour, M. Ghafoori and N. Jalali, Carpathian Journal of Earth and Environmental Sciences 6, 297-308 (2011)

[10] A. Rashki, D.G. Kaskaoutis, P.G. Eriksson, M. Qiang and P. Gupta, Aeolian Research 5, 51-62 (2012)

[11] H.K.H. Furman, Indoor and Built Environment 12(6), 419-426 (2003)

[12] A.S. Goudie and N.J. Middleton, Desert Dust in the Global System, Springer Science \& Business Media (2006)

[13] H.R. Khalesifard and H. Panahifar, In Optics and Photonics for Energy and the Environment, EM4A-1 (2015)

[14] F. Abdi Vishkaee, C. Flamant, J. Cuesta, P. Flamant and H.R. Khalesifard, Journal of Geophysical Research: Atmospheres 116(D5), D05206 (2011)
[15] O. Dubovik, A. Smirnov, B.N. Holben, M.D. King, Y.J. Kaufman, T.F. Eck and I. Slutsker, Journal of Geophysical Research: Atmospheres 105(D8), 9791-9806 (2000)

[16] A. Shimizu, N. Sugimoto, I. Matsui, K. Arao, I. Uno, T. Murayama, N. Kagawa, K. Aoki, A. Uchiyama and A. Yamazaki, Journal of Geophysical Research: Atmospheres 109(D19), D19S17 (2004)

[17] N. Sugimoto, I. Uno, M. Nishikawa, A. Shimizu, I. Matsui, X. Dong, Y. Chen and H. Quan, Geophysical Research Letters 30(12), 1640 (2003)

[18] M. Tesche, A. Ansmann, D. Müller, D. Althausen, R. Engelmann, V. Freudenthaler and S. Groß, Journal of Geophysical Research: Atmospheres 114(D13), D13202 (2009)

[19] C. Weitkamp (ed.), Lidar: Range-Resolved Optical Remote Sensing of the Atmosphere, Springer-Verlag New York, 102 (2006) 